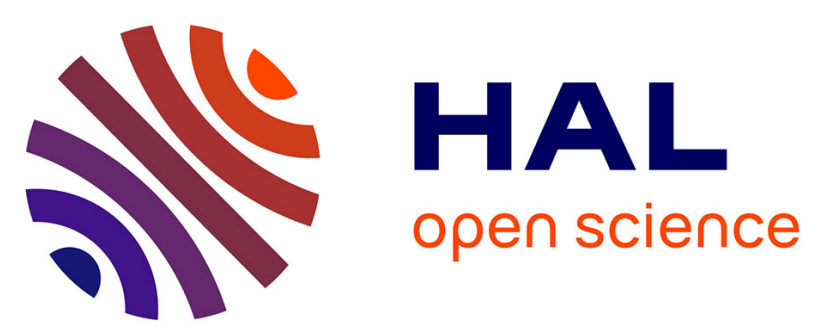

\title{
Effect of Eu substitution on the crystallographic and magnetic properties of the BiMn2O5 oxide obtained by urea combustion
}

Rafael Ferreira, Maria Elenice dos Santos, Cassio Morilla-Santos, Ronan Lebullenger, Octavio Peña, Paulo Noronha Lisboa-Filho

\section{To cite this version:}

Rafael Ferreira, Maria Elenice dos Santos, Cassio Morilla-Santos, Ronan Lebullenger, Octavio Peña, et al.. Effect of Eu substitution on the crystallographic and magnetic properties of the BiMn2O5 oxide obtained by urea combustion. Ceramics International, 2014, 40 (8, part B), pp.13643-13648. 10.1016/j.ceramint.2014.05.091 . hal-01015572

\section{HAL Id: hal-01015572 \\ https://hal.science/hal-01015572}

Submitted on 22 Mar 2016

HAL is a multi-disciplinary open access archive for the deposit and dissemination of scientific research documents, whether they are published or not. The documents may come from teaching and research institutions in France or abroad, or from public or private research centers.
L'archive ouverte pluridisciplinaire HAL, est destinée au dépôt et à la diffusion de documents scientifiques de niveau recherche, publiés ou non, émanant des établissements d'enseignement et de recherche français ou étrangers, des laboratoires publics ou privés. 
Effect of Eu substitution on the crystallographic and magnetic properties of the $\mathrm{BiMn}_{2} \mathrm{O}_{5}$ oxide obtained by urea combustion

R. A. Ferreira ${ }^{a, b^{*}} ;$ M. E. dos Santos ${ }^{a, b} ;$ C. Morilla-Santos ${ }^{c} ;$ R. Lebullenger ${ }^{b}$; O. Peña ${ }^{\text {b. P. N. Lisboa-Filho }}{ }^{\text {d }}$

aPOSMAT - Programa de Pós-Graduação em Ciência e Tecnologia de Materiais, UNESP - Univ Estadual Paulista, Bauru, SP, Brazil.

${ }^{\mathrm{b}}$ Institut des Sciences Chimiques de Rennes - UMR 6226, Université de Rennes 1, France.

'Instituto de Tecnologia para o Desenvolvimento - LACTEC, Curitiba, PR, Brazil

${ }^{\mathrm{d}}$ Faculdade de Ciências, UNESP - Univ Estadual Paulista, Departamento de Física, Bauru, SP, Brazil.

\begin{abstract}
Polycrystalline oxide materials with nominal compositions $\mathrm{BiMn}_{2} \mathrm{O}_{5}$ and $\mathrm{Bi}_{0.9} \mathrm{Eu}_{0.1} \mathrm{Mn}_{2} \mathrm{O}_{5}$ were obtained by urea combustion. Crystallographic studies using X-ray diffraction and Rietveld Refinement techniques showed the formation of single-phase samples for both compositions, crystallizing in a mullite-type orthorhombic perovskite structure, space group Pbam $(Z=4)$. Replacement of $\mathrm{Bi}^{+3}$ by $\mathrm{Eu}^{+3}$ promoted a slight distortion and a unit cell contraction due to a decrease of the c-parameter for $\mathrm{Bi}_{0.9} \mathrm{Eu}_{0.1} \mathrm{Mn}_{2} \mathrm{O}_{5}$. The SEM/EDX techniques confirmed the formation of single-phase materials with excellent mapping distribution. Magnetic measurements showed different behaviors: $\mathrm{BiMn}_{2} \mathrm{O}_{5}$ is an antiferromagnet (AFM) with a Néel temperature $\left(T_{N}\right)$ of $41 \mathrm{~K}$ and a Curie-Weiss temperature $\Theta_{\mathrm{cW}}$ of $-277 \mathrm{~K}$, while $\mathrm{Bi}_{0.9} \mathrm{Eu}_{0.1} \mathrm{Mn}_{2} \mathrm{O}_{5}$ displayed a ferrimagnetic behavior with a $T_{C}$ of $44 \mathrm{~K}$ and $\Theta_{C w}$ of $-270 \mathrm{~K}$. The role of $\mathrm{Eu}^{+3}$ and the mechanisms responsible for the magnetic transition are discussed on the basis of chemical bonds and exchange interactions:-
\end{abstract}

\title{
Keywords
}

A. Powders: chemical preparation, B. X-ray methods, C. Magnetic properties ;

D. Perovskites. 


\section{Introduction}

Multiferroics is a material class which simultaneously presents two or more primary ferroic orders such as ferroelectricity, ferroelasticity and (anti-) ferromagnetism when an electric field or a magnetic field are applied. The capacity of a material to couple two or more ferroic properties is due to the presence of two different types of cations: i) cations with electronic configuration $n s^{2}$ for which the lone pair is responsible for ferroelectricity; ii) cations with $d^{n}$ or $f^{n}$ partially-filled subshells, accountable for the magnetic ordering. Thus, these materials may present various properties such as magnetoelectricity, magnetooptical response, magneto-elasticity and ferroelasticity. Research on these materials attracts a great interest from the scientific and technological points of view since they can be used in spintronic and magneto-optical devices or as low-field magnetic sensors ${ }^{[1-7]}$

Although these materials are subject of fascination in basic physics and of great interest in applied research, only few oxides can be classified as multiferroics with potential possibilities in technological applications. Manganite oxides of the $\mathrm{RMn}_{2} \mathrm{O}_{5}$ family ( $\mathrm{R}$ a lanthanide, Yttrium or Bismuth), crystallizing with a mullite-type perovskite structure and space group Pbam, have attracted much attention due to their multiferroic properties such as magnetoelectricity and magnetodielectricity ${ }^{[8-10]}$.

Among this family, $\mathrm{BiMn}_{2} \mathrm{O}_{5}$ has been extensively investigated. The two manganese ions have different oxidation states: $\mathrm{Mn}^{4+}$ occupies the octahedral sites ( $4 f$ site) coordinated by six oxygen anions, while $\mathrm{Mn}^{3+}$ is located in a 
distorted tetragonal pyramidal site ( $4 h$ site) coordinated by five oxygen anions. The $\mathrm{Bi}^{3+}$ ions ( $4 \mathrm{~g}$ site) are coordinated to eight oxygen atoms and form $\mathrm{BiO}_{8}$ polyhedra. These polyhedra are responsible for the interconnection between both manganese cations localized at the octahedral and tetragonal pyramidal sites $^{[11]}$. The mixed-valent manganese ions occupying different crystallographic sites lead to the formation of a magnetic structure with two different magnetic sublattices. $\mathrm{BiMn}_{2} \mathrm{O}_{5}$ orders below $39 \mathrm{~K}$ in a noncollinear commensurate magnetic structure with a propagation vector $k=(1 / 2,0,1 / 2)$, in contrast to the $\mathrm{RMn}_{2} \mathrm{O}_{5}$ series, incommensurate with $\mathrm{k}=\left(1 / 2,0, k_{\mathrm{z}}\right)^{[12,13]}$. The magnetization curves for all members of the $\mathrm{RMn}_{2} \mathrm{O}_{5}$ family present a typical antiferromagnetic behavior with Néel temperatures close to $40 \mathrm{~K}^{[11-15]}$.

This paper aims to demonstrate, first, that the urea combustion is an adequate synthesis method to obtain multiferroic materials and, secondly, to investigate the role of the $\mathrm{Eu}^{3+}$ ions as improving dopants for the $\mathrm{BiMn}_{2} \mathrm{O}_{5}$ properties. In particular, the X-ray diffraction analysis and Rietveld refinement should allow correlating the modifications of the magnetic behavior of the $\mathrm{RMn}_{2} \mathrm{O}_{5}$ family when the $\mathrm{Bi}$ element is partially substituted by Eu.

\section{Materials and Methods}

The oxide materials $\mathrm{BiMn}_{2} \mathrm{O}_{5}$ and $\mathrm{Bi}_{0.9} \mathrm{Eu}_{0.1} \mathrm{Mn}_{2} \mathrm{O}_{5}$ were obtained by the urea combustion reaction method ${ }^{[16,17]}$. In a first step, $\mathrm{MnO}, \mathrm{Bi}_{2} \mathrm{O}_{3}$ and $\mathrm{Eu}_{2} \mathrm{O}_{3}$ precursors (99,99\% purity Aldrich) were weighted and dissolved separately in a concentrated solution of nitric acid. Then, these solutions were mixed under agitation with appropriate amounts of urea dissolved in water. The ratio of the 
urea amount $(R)$ to the corresponding nitrates was obtained using equation 1 [16].

$$
\varphi=-R \frac{\left[+4{ }_{(\mathrm{C})}-2_{(\mathrm{O})}+2\left(0_{(\mathrm{N})}+2.1_{(\mathrm{H})}\right)\right]}{\left[+3_{(\mathrm{Bi})}+3\left(0_{(\mathrm{N})}+3 .-2_{(\mathrm{O})}\right)\right]+2\left[+3_{(\mathrm{Mn})}+2\left(0_{(\mathrm{N})}+3 \cdot-2{ }_{(0)}\right)\right]}
$$

where $\varphi$ is a parameter which defines the oxidize/reduction reaction conditions and, for this work, taken as 3 . Numbers in numerator and denominator are the oxidation state of elements which for nitrogen was taken as zero.

The obtained products were then heated to $500^{\circ} \mathrm{C}$ until complete combustion. Powders were progressively calcined in air at $600{ }^{\circ} \mathrm{C}$ for 4 hours and then at $700{ }^{\circ} \mathrm{C}$ and $800{ }^{\circ} \mathrm{C}$ for 4 hours in each temperature with intermediate grinding after each calcination temperature. Similar procedure was adopted for the europium-doped sample with a final calcination at $900^{\circ} \mathrm{C}$ for 4 hours. The final products were grinded in an agate mortar and characterized by different techniques.

The homogeneity of the samples was confirmed by energy dispersive Xray mapping (EDX) and scanning electronic microscopy SEM observations (Philips model FEI Inspect S50). X-ray diffraction (XRD) patterns were registered with a Rigaku Rint DMAX-2100/PC diffractometer using $\mathrm{Cu} \mathrm{K}_{\alpha}$ radiation $(1.5406 \AA)$. The $2 \theta$ scans were carried out at room temperature from $10^{\circ}$ to $90^{\circ}$, with fixed time mode of $1.6 \mathrm{~s}$ and a step of $0.02^{\circ}$. Structural refinements were performed by the Rietveld method ${ }^{[18,19]}$ using the GSAS program ${ }^{[20]}$, the JCPDS phase identification and the ICSD (2003) structural database. The diffraction profiles were modeled using the pseudo-Voigt Thompson-Cox-Hastings ( $\mathrm{TCH}$ ) function ${ }^{[21]}$. Magnetization measurements were 
performed using a PPMS Quantum Design 6000 magnetometer with zero field cooling (ZFC) and field cooling (FC) data collected between $2 \mathrm{~K}$ and $300 \mathrm{~K}$ under an applied field of $1 \mathrm{kOe}$.

\section{Results and Discussions}

\subsection{SEM Analysis and Elements Mapping}

Figures 1(a) and 1(c) present SEM images of $\mathrm{BiMn}_{2} \mathrm{O}_{5}$ and $\mathrm{Bi}_{0.9} \mathrm{Eu}_{0.1} \mathrm{Mn}_{2} \mathrm{O}_{5}$ powder specimens. A homogeneous distribution of grains can be observed with average sizes close to $200 \mathrm{~nm}$ and $300 \mathrm{~nm}$, for the non-doped and the doped samples, respectively. The difference in the particle sizes can be attributed to the calcination procedure: $\mathrm{T}_{(\max )}=800^{\circ} \mathrm{C}$ (calcination total time $=$ 12h) for $\mathrm{BiMn}_{2} \mathrm{O}_{5}$ and $\mathrm{T}_{(\max )}=900^{\circ} \mathrm{C}$ (calcination total time $=16 \mathrm{~h}$ ) for $\mathrm{Bi}_{0.9} \mathrm{Eu}_{0.1} \mathrm{Mn}_{2} \mathrm{O}_{5}$. These two parameters (temperature and time) are known to enhance the sintering phenomena and induce an increase of particles size, as it occurred in the case of the $\mathrm{Bi}_{0.9} \mathrm{Eu}_{0.1} \mathrm{Mn}_{2} \mathrm{O}_{5}$ material

Heat-treatments performed at $900^{\circ} \mathrm{C}$ for the Eu doped sample was made considering it crystallized in a monophasic solid solution at this temperature. Otherwise, $\mathrm{BiMn}_{2} \mathrm{O}_{5}$ sample was crystallized like a monophasic solid solution in $800^{\circ} \mathrm{C}$. This were observed using the XRD associated with Rietveld Refinement and will be discussed on the section 3.2.

The elements distribution was checked by EDX analysis by mapping a large surface of compacted powders. Figures $1(b)$ and $1(d)$ show a uniform distribution of all elements $(\mathrm{Bi}, \mathrm{Eu}, \mathrm{Mn}$ and $\mathrm{O})$. Quantitative analyses of both 
samples by SEM-EDX confirmed the expected stoichiometric ratios of the constituent elements and the results are given in Table 1.

\subsection{X-Ray Powder diffraction and Rietveld Refinement}

The X-ray diffraction data $(X R D)$ of both samples were refined by the Rietveld method. Figures 2(a) and 3 show a good agreement between the calculated and observed data for $\mathrm{BiMn}_{2} \mathrm{O}_{5}$ and $\mathrm{Bi}_{0.9} \mathrm{Eu}_{0.1} \mathrm{Mn}_{2} \mathrm{O}_{5}$, respectively. Both materials crystallize in a mullite-type orthorhombic structure, space group Pbam and $\mathrm{Z}=4$. In this structure, $\mathrm{Mn}$ ions are found in two different crystallographic sites: $\mathrm{Mn}^{4+}$ ions occupy the octahedral pyramidal site (4f) coordinated to six oxygen atoms, whereas the $\mathrm{Mn}^{3+}$ ions occupy the tetragonal pyramidal site $(4 h)$ coordinated to five oxygen atoms. The $\mathrm{Bi}^{3+}$ ions sit at the $4 g$ sites and are coordinated to eight oxygen atoms forming $\mathrm{BiO}_{8}$ polyhedra ${ }^{[11-14]}$. Based on our refined data, we may suppose that the $\mathrm{Eu}^{3+}$ ions replace $\mathrm{Bi}^{3+}$ at the $4 g$ site and do not modify the crystal structure of the host material.

Figure 2(b) is a schematic representation of the crystallographic structure along the $c$-axis. In this representation distorted $\mathrm{Mn}^{4+} \mathrm{O}_{6}$ octahedral are environments of the $\mathrm{Mn}^{4+}$ ( $\mathrm{Mn} 1$ atoms) which form infinite linear chains along the $c$-axis, sharing edges via the $\mathrm{O}_{3}$ and $\mathrm{O}_{4}$ oxygen. $\mathrm{Mn}^{3+}$ (Mn2 atoms) occupy $\mathrm{Mn}^{3+} \mathrm{O}_{5}$ distorted tetragonal pyramids and have as neighbors five oxygen atoms. These units present four oxygen atoms in different positions (two $\mathrm{O}_{1}$ and two $\left.\mathrm{O}_{2}\right)$ are in a square planar configuration and fifth oxygen $\left(\mathrm{O}_{4}\right)$ is in an axial position at a longer distance $(2.111 \AA)$. The connections between pyramids and octahedrons are along the $c$-axis via $\mathrm{O}_{4}$ and $\mathrm{O}_{2}$. 
Table 2 indicates the structural parameters obtained by the Rietveld refinement. Tables 3 and 4 list the most important interatomic distances and angles concerning the non-doped $\mathrm{BiMn}_{2} \mathrm{O}_{5}$ and doped $\mathrm{Bi}_{0.9} \mathrm{Eu}_{0.1} \mathrm{Mn}_{2} \mathrm{O}_{5}$ materials, respectively, making emphasis on the different polyhedra $\mathrm{Mn}^{4+} \mathrm{O}_{6}$, $\mathrm{Mn}^{3+} \mathrm{O}_{5}, \mathrm{Bi}^{3+} \mathrm{O}_{8}$ and $\mathrm{Eu}^{3+} \mathrm{O}_{8}$.

The average $\mathrm{Mn}-\mathrm{O}$ distances obtained in this work $\left(<\mathrm{Mn}^{+4}-\mathrm{O}\right\rangle=1.897 \AA$ and $\left\langle\mathrm{Mn}^{+3}-\mathrm{O}\right\rangle=1.920 \AA$ (Table 3$)$ ) are slightly lower than those reported by Muñoz et al from Neutron Powder Diffraction data $\left(\left\langle\mathrm{Mn}^{+4}-\mathrm{O}\right\rangle=1.916 \AA\right.$ and $\left.<\mathrm{Mn}^{+3}-\mathrm{O}>=1.948 \AA\right)^{[11]}$. This fact is associated to a contraction of the octahedral and pyramidal sites. Reported results of structural parameters for samples synthesized by other methods, such as hydrothermal ${ }^{[22]}$ and solid state reactions ${ }^{[8,10]}$ are in agreement with the data found in this work. However, we should recall the fact that the heat-treatment parameters ( $\mathrm{T}^{\circ}$ and total time) adopted in this work $\left(800-900^{\circ} \mathrm{C}\right.$ and $12 \mathrm{~h}$ and $\left.16 \mathrm{~h}\right)$ are lower than those mentioned by others authors, and it confirms that urea stress the fact that the heat-treatment adopted in this work is lower than all others mentioned above, and it confirms that urea combustion is an excellent method to obtain single-phase oxide materials at low temperatures.

The $\mathrm{Eu}^{3+}$ substitution at the $\mathrm{Bi}^{3+}$ site leads to a slight contraction of the unit cell (Table 2) due to the smaller ionic radius of $\mathrm{Eu}^{+3}(1.06 \AA)$ compared to $\mathrm{Bi}^{+3}(1.17 \AA)$. The lattice contraction occurs predominantly on the lattice parameters $\mathrm{a}$ and $\mathrm{c}$, whereas no significant variation is observed for the b-parameter. Slight variations in the positions of the (001), (002), (003) and (004) planes explain the modifications of the octahedral sites occupied by $\mathrm{Mn}^{+4}$ ions that form chains along the $c$ axis ${ }^{[23-25]}$. 
The average distance $\mathrm{Mn} 1-\mathrm{O}$ for sample $\left.\mathrm{BiMn}_{2} \mathrm{O}_{5}(<\mathrm{Mn} 1-\mathrm{O}\rangle=1.897 \AA\right)$ is larger than the $(\langle\mathrm{Mn} 1-\mathrm{O}\rangle=1.887 \AA)$, value obtained for the Eu-doped sample suggesting that the insertion of the $\mathrm{Eu}^{3+}$ ions in the $4 g$ position promotes a contraction of this site. The distorted pyramidal polyhedra $\mathrm{Mn}^{3+} \mathrm{O}_{5}$ of the $\mathrm{Bi}_{0.9} \mathrm{Eu}_{0.1} \mathrm{Mn}_{2} \mathrm{O}_{5}$ suffers a contraction due to the $\mathrm{Mn}^{3+}$ located at the $4 h$ position, the Mn2-O4 distance changing from $2.111 \AA$ to $2.088 \AA$, for the non-doped and Eu-doped compounds, respectively (Tables 3 and 4). Such stretching of the Mn2-O distance in the $\mathrm{Mn}^{3+} \mathrm{O}_{5}$ pyramid tetrahedral is probably associated to the Jahn-Teller effect of the $\mathrm{Mn}^{3+}$ ion.

Other distances related to the chemical bonds, such as $<\mathrm{Bi}-\mathrm{O}>$ and $<\mathrm{Mn1}-\mathrm{Mn} 1>$, slightly decrease in the doped $\mathrm{Bi}_{0.9} \mathrm{Eu}_{0.1} \mathrm{Mn}_{2} \mathrm{O}_{5}$ sample, whereas the $<\mathrm{Mn} 2-\mathrm{Mn} 2>$ average distance stays invariant. This fact confirms the larger distortion of the tetragonal pyramidal site, since the average distances $<$ Mn1O $>$ and $<$ Mn2-O $>$ also decrease with doping.

\subsection{Magnetic Measurements}

Figure 4 shows the ZFC/FC cycles of $\mathrm{BiMn}_{2} \mathrm{O}_{5}$ and $\mathrm{Bi}_{0.9} \mathrm{Eu}_{0.1} \mathrm{Mn}_{2} \mathrm{O}_{5}$ measured under an applied magnetic field of $1 \mathrm{kOe}$. Both samples present an antiferromagnetic-type ZFC magnetization, with a maximum at $\mathrm{T}=\mathrm{T}_{\mathrm{N}}$ of $41 \mathrm{~K}$ and $37 \mathrm{~K}$, respectively. During the FC mode, the magnetization increases abruptly at the ferromagnetic ordering temperature $\mathrm{T}_{\mathrm{C}}$, defined in this work as the intersection of two straight lines sketched just above and just below $\mathrm{T}_{\mathrm{C}}$. The $\mathrm{T}_{\mathrm{C}}$ values for both systems are identical, $44.3(0.2) \mathrm{K}$, meaning that $\mathrm{Mn}^{3+}-\mathrm{Mn}^{4+}$ 
ferromagnetic interactions have been optimized through the coupling between the tetrahedral and octahedral sublattices.

Two experimental facts are worth to be noticed in Figure 4: firstly, the large difference in magnetization values between both samples, in the ordered state; secondly, the quite constant evolution of the FC magnetization below 20-30 $\mathrm{K}$ for the Eu-doped sample. Knowing that $\mathrm{Eu}^{3+}$ is a VanVleck ion, no intrinsic magnetism may be expected from it at these temperatures ${ }^{[26]}$; in consequence, the large $\mathrm{M}_{\mathrm{FC}}$ magnetization in the $\mathrm{Bi}_{0.9} \mathrm{Eu}_{0.1} \mathrm{Mn}_{2} \mathrm{O}_{5}$ system must be attributed to a better ferromagnetic coupling between the manganese moments, probably due to the contraction of the unit cell when replacing $\mathrm{Bi}$ by Eu. The observed phenomena for Eu substitution is attributed to a Morin-type transition, usually observed in Eu doped systems ${ }^{[27]}$.

Modifications of the lattice parameters and probably the accompanying distortion of the lattice due to a Jahn-Teller effect of the $\mathrm{Mn}^{3+}$ ion ${ }^{[9]}$, may also create some AFM canting of the magnetic moments, bringing about an additional ferromagnetic component in the Eu-doped case, thus increasing the ferromagnetic contribution at low temperatures.

The second fact pointed above, that is the quite constant thermal evolution of $\mathrm{M}_{\mathrm{FC}}$ magnetization at low temperature in the case of the Eu-doped material, may be attributed to anisotropic features which are quite important in the case of the full-europium mullite-type perovskite structure, EuMn ${ }_{2} \mathrm{O}_{5}$, in contrast to $\mathrm{BiMn}_{2} \mathrm{O}_{5}$ which presents none ${ }^{[15]}$. Our experimental conditions for powdered samples may provoke some reorientation by the applied field, of grains and/or particles due to the magnetic anisotropy, contrary to the reports made by Golovenchits et al in single crystal samples ${ }^{[15]}$. This anisotropy may 
also be responsible of the much smaller hysteresis between the ZFC and FC modes in the case of $\mathrm{BiMn}_{2} \mathrm{O}_{5}$, even though this system was reported by Golovenchits et al as isotropical from the magnetic point of view. Other authors have also found weak hysteretic behavior in $\mathrm{BiMn}_{2} \mathrm{O}_{5}$ samples ${ }^{[11]}$. Magnetic anisotropy may also be the explanation of small differences in the values of $T_{N}$ (39 $\mathrm{K}$ in ref. [11], $40 \mathrm{~K}$ in ref. [15], $41 \mathrm{~K}$ in this work).

The inset, Figure 4, shows the inverse magnetic susceptibility for both samples, at the paramagnetic state. Analysis of $1 / \chi-v s-T$ by linear regression in the range $[100-300 \mathrm{~K}]$ allows finding the Curie-Weiss temperature $\Theta_{W c}$ and the magnetic effective moment $\mu_{\text {eff }}$ for both samples, with values of $\Theta_{w c}=-277 \mathrm{~K}$ and $-270 \mathrm{~K}$, and $\mu_{\text {eff }}=6.69 \mu_{\mathrm{B}}$ and $6.90 \mu_{\mathrm{B}}$, for $\mathrm{BiMn}_{2} \mathrm{O}_{5}$ and $\mathrm{Bi}_{0.9} \mathrm{Eu}_{0.1} \mathrm{Mn}_{2} \mathrm{O}_{5}$, respectively. These values are quite similar to those reported in the literature for a $\mathrm{BiMn}_{2} \mathrm{O}_{5}$ perovskite obtained by hydrothermal, solid-state and citrate techniques, $\Theta_{\mathrm{WC}} \sim-270 \mathrm{~K}$ and $\mu_{\mathrm{eff}}=6.9 \mu_{\mathrm{B}}{ }^{[8-11]}$, but somewhat higher than the magnetic moment of $6.24 \mu_{\mathrm{B}}$ expected from the contributions of non-interacting $\mathrm{Mn}^{3+}$ and $\mathrm{Mn}^{4+}$ ions in the paramagnetic state.

Some considerations must be forwarded regarding the coexistence of an AFM and a FM ordering behaviors. It is quite evident that the quite large negative Curie-Weiss temperature ( -270 and $-277 \mathrm{~K}$ found in this work) is indicative of a ferrimagnetic nature of both materials, which may be extrapolated to other components of the $\mathrm{RMn}_{2} \mathrm{O}_{5}$ family ${ }^{[8-14]}$. 


\section{Conclusions}

In this work we demonstrated that single phase materials $\mathrm{BiMn}_{2} \mathrm{O}_{5}$ and $\mathrm{Bi}_{0.9} \mathrm{Eu}_{0.1} \mathrm{Mn}_{2} \mathrm{O}_{5}$ were successfully obtained by the urea combustion method, excellent technique to obtain complex oxide materials at intermediate temperatures with good particle size and uniform element distribution. Rietveld refinement of the $\mathrm{XRD}$ data agrees with a substitution of $\mathrm{Bi}^{+3}$ by $\mathrm{Eu}^{+3}$ in the same crystallographic sites, both cations having similar ionic radius. The magnetic behavior changes significantly when $\mathrm{Bi}^{+3}$ ions are substituted by $\mathrm{Eu}^{+3}$. Both compositions order below $40 \mathrm{~K}$, with $\mathrm{BiMn}_{2} \mathrm{O}_{5}$ in an antiferromagnetic state while $\mathrm{Bi}_{0.9} \mathrm{Eu}_{0.1} \mathrm{Mn}_{2} \mathrm{O}_{5}$ presents a ferrimagnetic behavior. This difference seems to be related to the commensurate magnetic structure of $\mathrm{BiMn}_{2} \mathrm{O}_{5}$ eventually becoming incommensurate with the substitution of $\mathrm{Bi}^{+3}$ by $\mathrm{Eu}^{+3}$. One of the key mechanisms is the lattice distortion, which modifies the strength of the exchange chains responsible of the ferrimagnetic behavior.

\section{Acknowledgments}

Authors are thankful to FAPESP GRANT 2007/08072-0 and 2013/07296-2. The authors also acknowledge the bilateral exchange programs France-Brazil CAPES-COFECUB, project no. 706/11. R.A. Ferreira and M.E. Santos in a Joint Ph.D. International Program, UNESP-Université de Rennes 1. 


\section{References}

[1] D. Khomskii, Physics 20 (2009) 2.

[2] A.H. Nicola, Journal of Physical Chemistry B 104 (2000) 6694.

[3] D.C. Jia, J.H. Xu, H. Ke, W. Wang, Y. Zhou, Journal of the European Ceramic Society 29 (2009) 3099.

[4] J. Rodriguez-Carvajal, G. Rousse, C. Masquelier, M. Hervieu, Physical Review Letters 81 (1998) 4660.

[5] N.A. Spaldin, S. Cheong, R. Ramesh, Physics Today 63 (2010) 38.

[6] B.L. Ahuja, A. Dashora, N.L. Heda, S. Tiwari, N.E. Rajeevan, M. Itou, Y. Sakurai, R. Kumar, Applied Physics Letters 97 (2010) 212502.

[7] A.L.G. Prette, M. Cologna, V. Sglavo, R. Raj, Journal of Power Sources 196 (2011) 2061 .8] Z.H. Sun, B.L. Ch, Jeng, S. Dai, K.J.Jin, Y.L. Zhou, H.B.Lu, Z.H. Chen, G.Z. Yang, Journal of Applied Physics 99 (2006) 084105

[9] K. S. Kumar, C. Venkateswaran, Journal of Physics D: Applied Physics, 44 (2011) 325001.

[10] D.K Shukla, S. Mollah, R. Kumar, P. Thakur, K.H Chae, W.K Choi, A. Banerjee, Journal of Applied Physics, 104 (2008) 033707.

[11] A. Muñoz, J.A. Alonso, M.T Casais, M.J Martínez Lopez, J.L. Martínez, M.T Fernadez-Díaz, Physical Review B, 65 (2002) 1444423(1-8).

[12] A. Muñoz, J. A. Alonso, M. J. Martínez-Lopez, J. L. Martínez, Physics Reviews B, 72 (2005) 184402.

[13] A. Muñoz, J.A. Alonso, M.T Casais, M.J Martínez Lopez, J.L. Martínez, M.T Fernadez-Díaz, European Journal Inorganic Chemistry, 4 (2005) 685-691.

[14] J.A. Alonso, M.T. Casais, M.J. Martínez-Lopes, J.L. Martínez, M.T. Fernández-Díaz, Journal Physics Condensed Matter, 9 (1997) 8515-8526.

[15] E.I. Golovenchits, V.A. Sanin, A.V. Babinskii, Journal of Experimental and Theoretical Physics, 85 (1997) 156-162.

[16] A.Civera, M. Pavese, G. Saracco, V. Specchia, Catalysis Today, 83 (2003) 199-211.

[17] D.A. Fumo, M.R. Morelli, A.M. Segadães, Materials Research Bulletin, 31 (1996) 1243-1255.

[18] H. Rietveld, Journal of applied Crystallography 2 (1969) 65-71. 
[19] H. Rietveld, Acta Crystallographica, 22 (1) (1967) 151-152.

[20] A. Larson, R. Von Dreele, General Structure Analysis System (GSAS), Report LAUR 86-748; Los Alamos National Laboratory.

[21] P. Thompson, D. Cox, J. Hastings, Journal of Applied Crystallography 20 (2) (1987) 79-83.

[22] L. H. Yin, B. Yuan, J. Chen, D. M. Zhang, Q. L. Zhang, J. Yang, J. M. Dai, W. H. Song, Y. P. Sun, Applied Physics Letters, 103 (2013) 152908.

[23] E. Granado, M.S Eleoterio, A.F. García-Flores, Physical Review. B, Condensed Matter and Materials Physics, 77 (2008) 134101(1-8).

[24] A.F. García-Flores, E. Granado, H. Martinho, C. Rettori, Journal of Applied Physics, 101 (2007) 09M106.

[25] A.F. García-Flores; E. Granado, H. Martinho, R.R. Urbano, C. Rettori, Physical Review B: Condensed Matter and Materials Physics, 73 (2006) 104411(1-6).

[26] J.H. Van Vleck, The Theory of Electric and Magnetic Susceptibilities, Oxford University Press (1932) p. 226.

[27] P. Allia, G. Barrera, B. Bonelli, F. S. Freyria, P. Tiberto, Journal Nanoparticles Resources (2013) 15:2118.

Tables Captions: 
Table 1. Stoichiometric Compositions of $\mathrm{BiMn}_{2} \mathrm{O}_{5}$ and $\mathrm{Bi}_{0.9} \mathrm{Eu}_{0.1} \mathrm{Mn}_{2} \mathrm{O}_{5}$ samples obtained by EDS-analysis.

Table 2. Rietveld XPD analysis result data for the samples obtained by combustion urea method. Data were collected at room temperature and the space group used was Pbam.

Table3. $\mathrm{BiMn}_{2} \mathrm{O}_{5}$ Specimen interatomic distances (in $\AA$ ) and select bonding angles (in degree) obtained by Rietveld Refinement Method at $298 \mathrm{~K}$.

Table4. $\mathrm{Bi}_{0.9} \mathrm{Eu}_{0.1} \mathrm{Mn}_{2} \mathrm{O}_{5}$ Specimen interatomic distances (in $\AA$ ) and select bonding angles (in degree) obtained by Rietveld Refinement Method at $298 \mathrm{~K}$.

\section{Figures Captions:}


Figure 1: a) Scanning electron micrograph of a representative samples of $\mathrm{BiMn}_{2} \mathrm{O}_{5}$ manganite powders obtained by the urea combustion method, followed by heat treatment in air at $800^{\circ} \mathrm{C}$ for 4 hours. b) Scanning elements analysis of the $\mathrm{BiMn}_{2} \mathrm{O}_{5}$ sample showing a homogenous elements distribution for Bismuth, Manganese and Oxygen. c) Scanning electron micrograph of representative samples of $\mathrm{Bi}_{0.9} \mathrm{Eu}_{0.1} \mathrm{Mn}_{2} \mathrm{O}_{5}$ powders obtained by the urea combustion method, followed by heat treatment in air at $900^{\circ} \mathrm{C}$ for 4 hours. d) Scanning elements analysis of the $\mathrm{Bi}_{0.9} \mathrm{Eu}_{0.1} \mathrm{Mn}_{2} \mathrm{O}_{5}$ sample showing a homogenous elements distribution for Europium, Bismuth, Manganese and Oxygen.

Figure 2. a) XRD Rietveld refinement for the $\mathrm{BiMn}_{2} \mathrm{O}_{5}$ sample heat-treated in air at $800^{\circ} \mathrm{C}$ for $4 \mathrm{~h}$. b) The structural models of $\mathrm{BiMn}_{2} \mathrm{O}_{5}$ with chain of $\mathrm{Mn}$ atoms along the c-axis.

Figure 3. XRD Rietveld refinement for the $\mathrm{Bi}_{0,90} \mathrm{Eu}_{0,10} \mathrm{Mn}_{2} \mathrm{O}_{5}$ sample heattreated in air at $800^{\circ} \mathrm{C}$ for $4 \mathrm{~h}$.

Figure 4. Magnetic susceptibility versus temperature at a constant applied field of $1 \mathrm{kOe}$. (Inset) Inverse of magnetic susceptibility vs temperature for an applied field of $1 \mathrm{kOe}$ for the $\mathrm{BiMn}_{2} \mathrm{O}_{5} \mathrm{Bi}_{0,90} \mathrm{Eu}_{0,10} \mathrm{Mn}_{2} \mathrm{O}_{5}$ samples. 

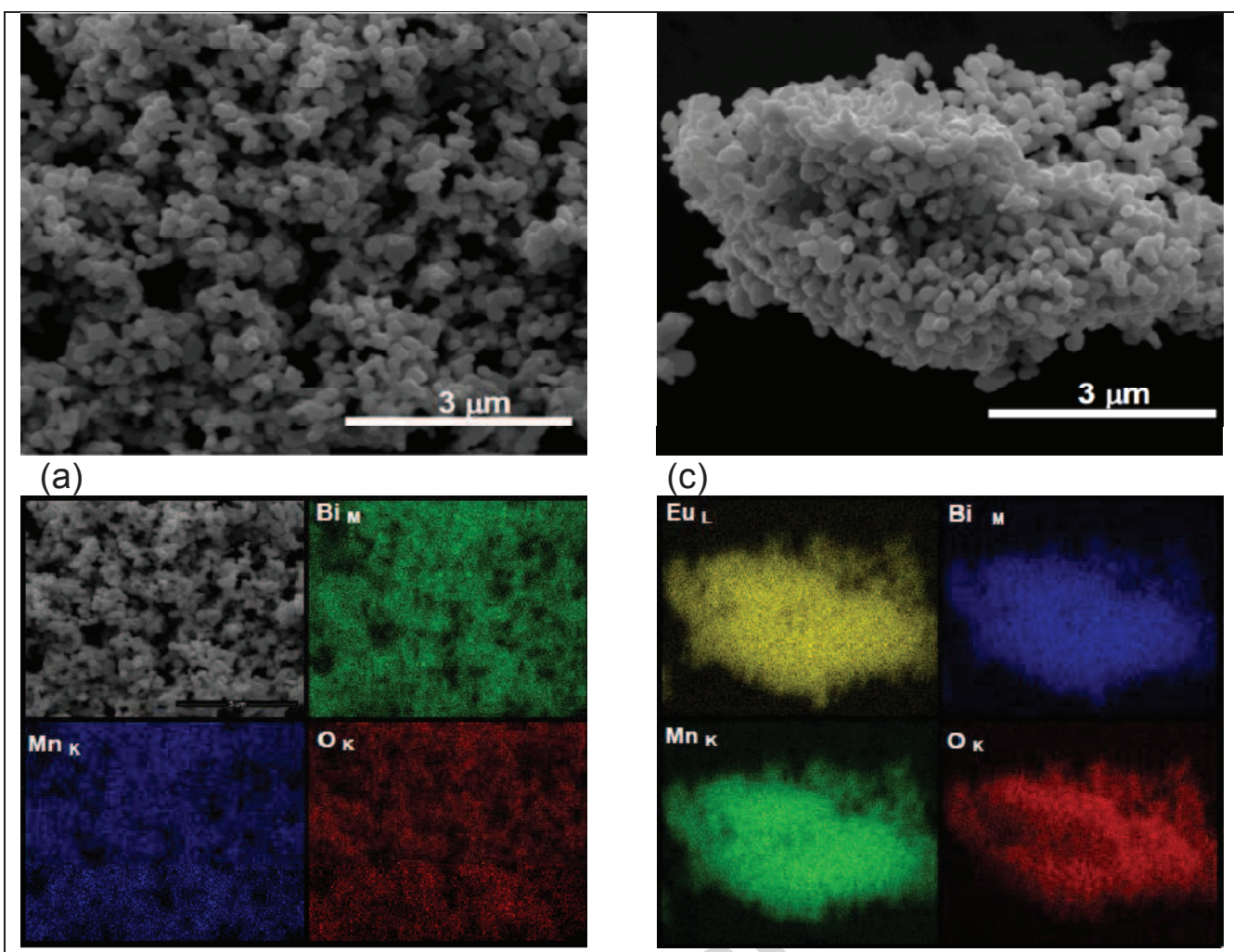

(b)

(d)

Figure 1. 


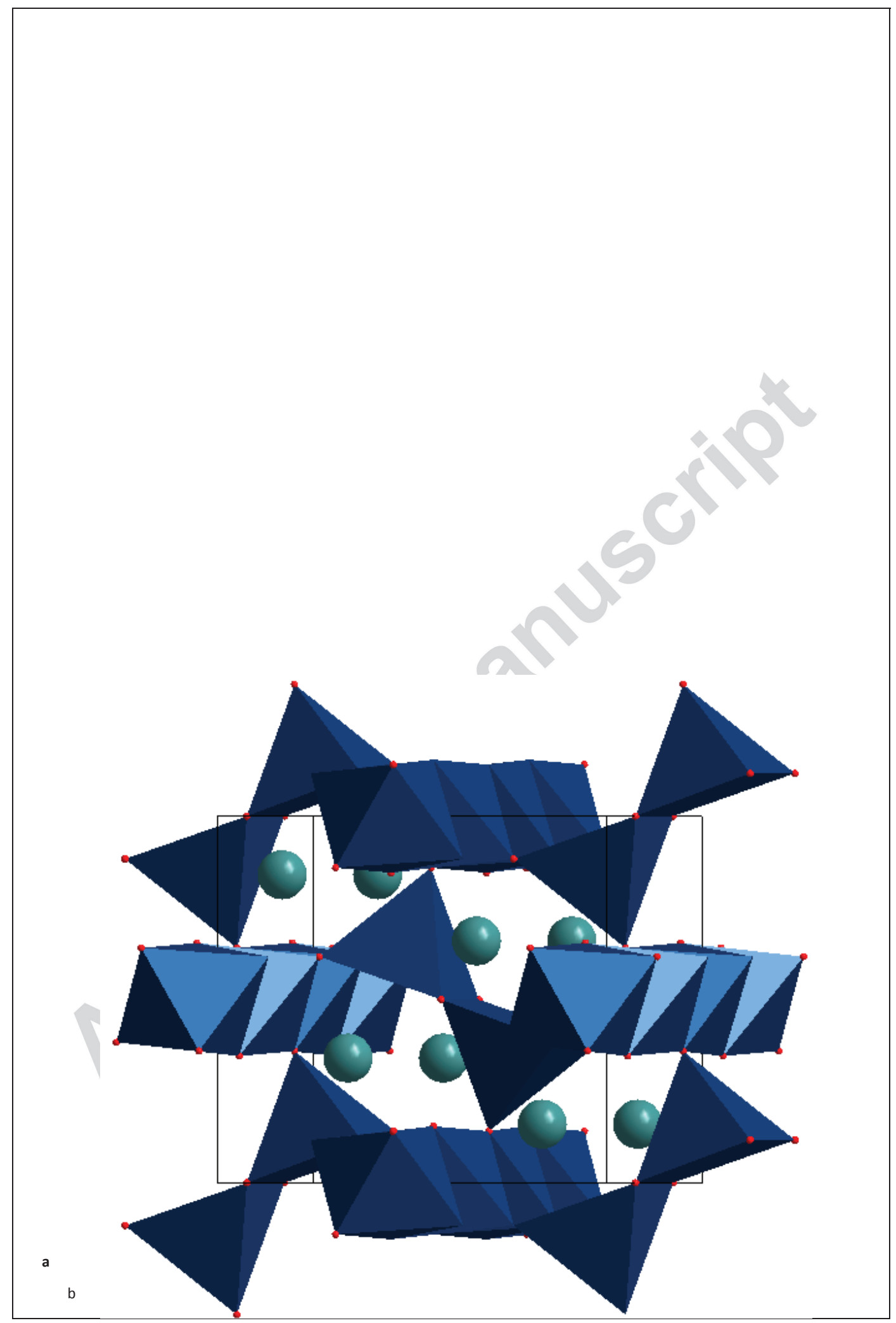

Figure 2. 


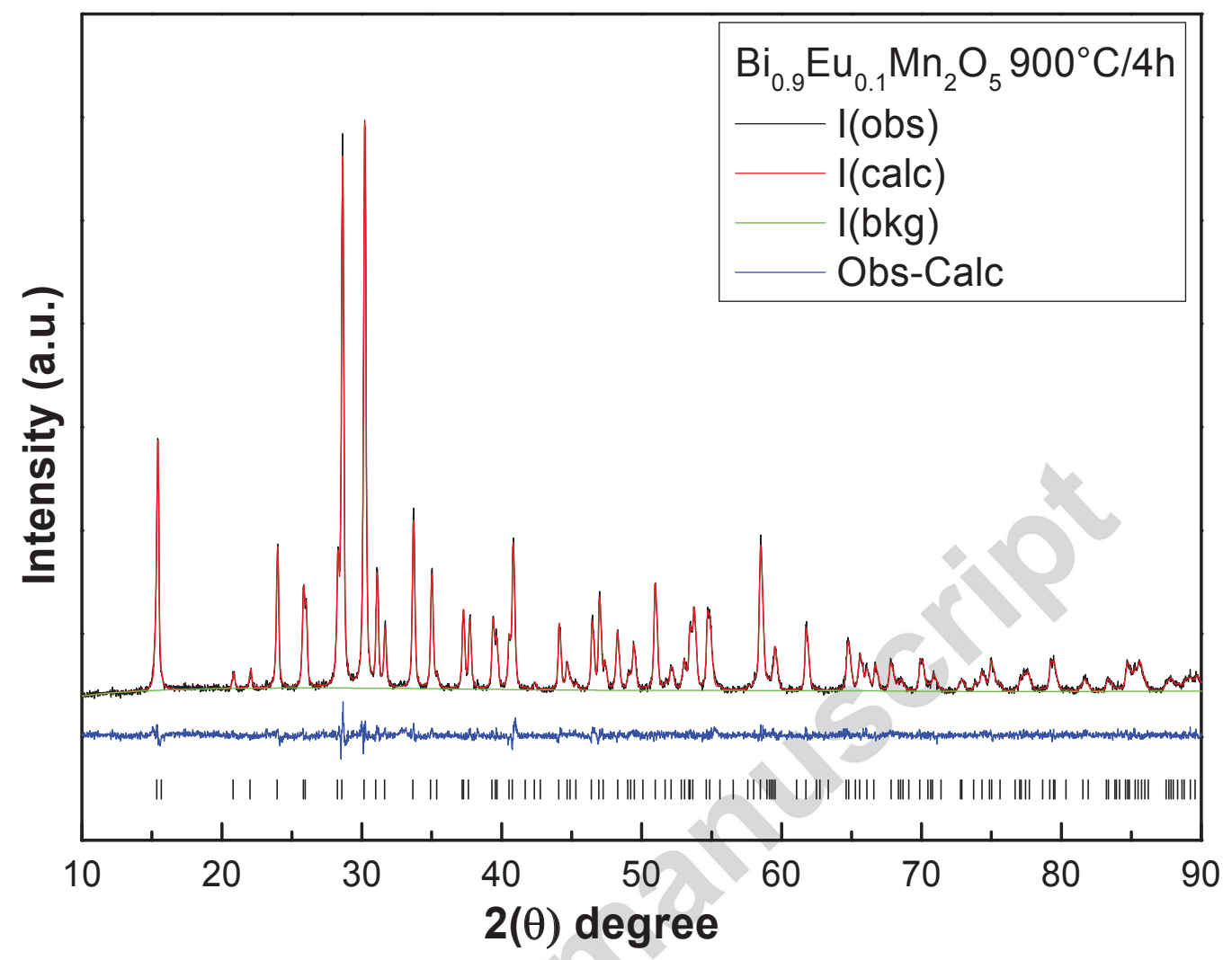

Figure 3. 


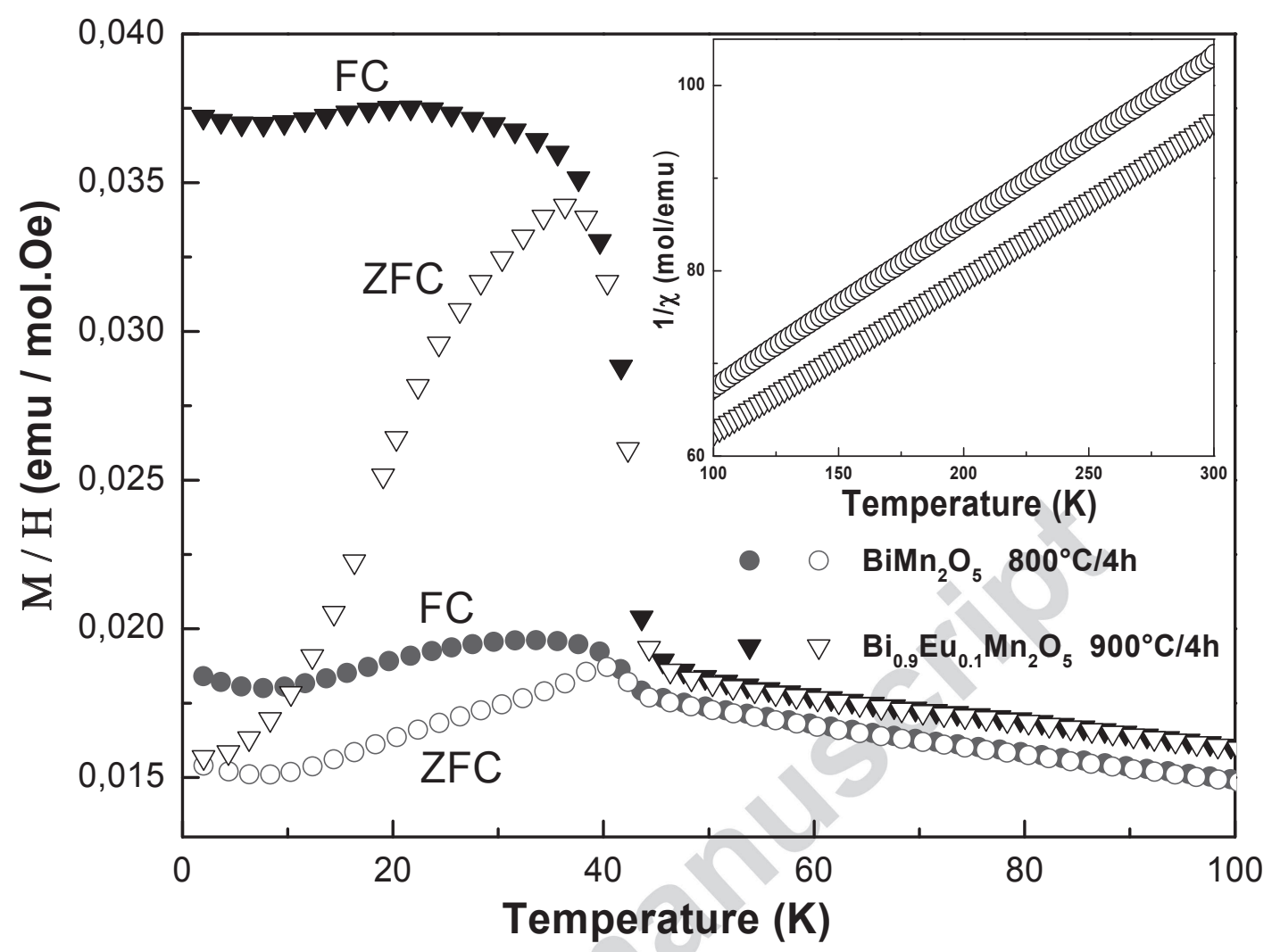

Figure 4. 
Table 1:

\begin{tabular}{|c|c|c|c|c|c|c|}
\hline \multirow[t]{2}{*}{ Sample } & \multicolumn{6}{|c|}{$\begin{array}{l}\text { Stoichiometric Values } \\
\text { ( } \% \text { weight } / \% \text { atomic) }\end{array}$} \\
\hline & \multicolumn{2}{|c|}{$\mathbf{B i}$} & \multicolumn{2}{|c|}{$\mathrm{Mn}$} & \multicolumn{2}{|c|}{ Eu } \\
\hline $\begin{array}{c}\text { Nominal Composition } \\
\mathrm{BiMn}_{2} \mathrm{O}_{5}\end{array}$ & 65.54 & 33.33 & 34.46 & 66.67 & - & - \\
\hline Experimental Composition & 64.20 & 31.90 & 35.80 & 68.10 & - & - \\
\hline $\begin{array}{c}\mathrm{Bi}_{0.96} \mathrm{Mn}_{2.04} \mathrm{O}_{5} \\
\text { Percentage Difference (\%) }\end{array}$ & 2.04 & 4.02 & 3.88 & 2.09 & - & - \\
\hline Nominal Composition & 60.06 & 30.00 & 35.09 & 66.67 & 4.85 & 3.33 \\
\hline Experimental Composition & 59.28 & 28.73 & 36.31 & 68.16 & 4.41 & 3.11 \\
\hline $\begin{array}{c}\mathrm{Bi}_{0.88} \mathrm{Eu}_{0.09} \mathrm{Mn}_{2.04} \mathrm{O}_{5} \\
\text { Percentage Difference (\%) }\end{array}$ & 1.31 & 4.23 & 3.47 & 3.00 & 9.97 & 6.66 \\
\hline
\end{tabular}

Table 2.

\begin{tabular}{|c|c|c|c|}
\hline $\begin{array}{c}\text { Nominal Composition } \\
\mathrm{BiMn}_{2} \mathrm{O}_{5} \\
\text { Space Group } \\
\text { Lattice parameter }(\AA) \\
\text { Volume }\left(\AA^{3}\right)\end{array}$ & 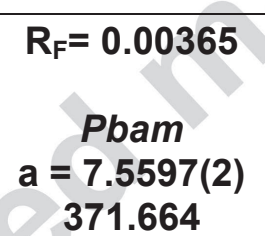 & $\begin{array}{c}\chi^{2}=1.083 \\
\alpha=\beta=y=90^{\circ} \\
b=8.5342(4)\end{array}$ & $\begin{array}{l}\text { Orthorhombic } \\
\text { System } \\
\text { c = } 5.7608(4)\end{array}$ \\
\hline $\begin{array}{c}\text { Nominal Composition } \\
\mathrm{Bi}_{0,90} \mathrm{Eu}_{0,10} \mathrm{Mn}_{2} \mathrm{O}_{5} \\
\text { Space Group } \\
\text { Lattice parameter }(\AA) \\
\text { Volume }\left(\AA^{3}\right)\end{array}$ & $\begin{aligned} R_{\mathrm{F}}= & 0.00356 \\
& P b a m \\
a= & 7.5522(8) \\
& 371.143\end{aligned}$ & $\begin{array}{c}\chi^{2}=1.091 \\
\alpha=\beta=y=90^{\circ} \\
b=8.5352(3)\end{array}$ & $\begin{array}{c}\text { Orthorhombic } \\
\text { System } \\
\text { c }=5.7577(0)\end{array}$ \\
\hline
\end{tabular}




\begin{tabular}{|c|c|c|c|}
\hline Mn1-O2 (x2) & 1.863 & Bi-O1 (x2) & 2.558 \\
\hline Mn1-O3 (x2) & 1.956 & $\mathrm{Bi}-\mathrm{O} 2(\times 2)$ & 2.309 \\
\hline Mn1-04 (x2) & 1.873 & $\mathrm{Bi}-\mathrm{O} 2(\times 2)$ & 2.847 \\
\hline \multirow{2}{*}{\multicolumn{2}{|c|}{$\begin{array}{c}<\mathrm{Mn} 1-\mathrm{O}>=1.897 \\
\mathrm{Mn}^{3+}-\mathrm{O} 5\end{array}$}} & $\mathrm{Bi}-\mathrm{O} 3$ & 2.368 \\
\hline & & $\mathrm{Bi}-03$ & 2.360 \\
\hline Mn2-01 (x2) & 1.863 & $<\mathrm{Bi}-\mathrm{O}>$ & 2.519 \\
\hline Mn2-O2 (x2) & 1.883 & \multicolumn{2}{|c|}{ Mn-Mn } \\
\hline Mn2-04 & 2.111 & Mn1-Mn1 & 2.785 \\
\hline \multirow{2}{*}{\multicolumn{2}{|c|}{$<\mathrm{Mn} 2-\mathrm{O}>=1.920$}} & Mn1-Mn1 & 2.976 \\
\hline & & Mn2-Mn2 & 2.975 \\
\hline \multicolumn{4}{|c|}{ Selected bonding angles } \\
\hline O3-Mn1-O3 & $81.0(2)$ & 01-Mn2-04 & 98.9(2) \\
\hline O3-Mn1-04 & $173.9(2)$ & O1-Mn2-O2 & $95.2(1)$ \\
\hline O3-Mn1-O4 & $97.2(4)$ & 01-Mn2-02 & $161.9(2)$ \\
\hline O3-Mn1-O2 & $94.5(1)$ & O4-Mn2-O2 & $97.7(3)$ \\
\hline O3-Mn1-O2 & $87.8(6)$ & $\mathrm{O} 2-\mathrm{Mn} 2-\mathrm{O} 2$ & $91.1(4)$ \\
\hline O4-Mn1-04 & 83.9(2) & Mn2-O1-Mn2 & $106.0(1)$ \\
\hline O4-Mn1-O2 & $86.3(1)$ & Mn1-O3-Mn1 & 99.0(0) \\
\hline O4-Mn1-02 & $91.5(4)$ & Mn1-04-Mn1 & $96.1(0)$ \\
\hline O2-Mn1-O2 & $177.5(2)$ & Mn1-O4-Mn2 & $130.5(5)$ \\
\hline 01-Mn2-01 & $74.0(0)$ & Mn1-O2-Mn2 & $126.5(5)$ \\
\hline
\end{tabular}

Table 3.

Table 4. 


\begin{tabular}{|c|c|c|c|}
\hline \multicolumn{2}{|c|}{$\mathrm{Mn}^{4+}-06$} & \multicolumn{2}{|c|}{$\mathrm{Bi}^{+3}-\mathrm{O} 8$} \\
\hline Mn1-O2 (x2) & 1.854 & $\mathrm{Bi}-\mathrm{O} 1$ (x2) & 2.498 \\
\hline Mn1-O3 (x2) & 1.941 & $\mathrm{Bi}-\mathrm{O} 2(x 2)$ & 2.332 \\
\hline Mn1-O4 (x2) & 1.861 & $\mathrm{Bi}-\mathrm{O} 2(\times 2)$ & 2.814 \\
\hline \multicolumn{2}{|c|}{$<\mathrm{Mn} 1-\mathrm{O}>=1.887$} & $\mathrm{Bi}-\mathrm{O} 3$ & 2.380 \\
\hline \multicolumn{2}{|c|}{$\mathrm{Mn}^{3+}-05$} & $\mathrm{Bi}-\mathrm{O} 3$ & 2.380 \\
\hline Mn2-01 (x2) & 1.914 & \multirow{2}{*}{\multicolumn{2}{|c|}{$\begin{array}{c}<\mathrm{Bi}-\mathrm{O}>=2.506 \\
\mathrm{Eu}^{+3}-08\end{array}$}} \\
\hline Mn2-O2 (x2) & 1.887 & & \\
\hline Mn2-O4 & 2.088 & Eu-01 (x2) & 2.554 \\
\hline \multicolumn{2}{|c|}{$<\mathrm{Mn} 2-0\rangle=1.938$} & Eu-O2 (x2) & 2.164 \\
\hline \multicolumn{2}{|c|}{ Mn-Mn } & Eu-O2 (x2) & 3.094 \\
\hline Mn1-Mn1 & 2.763 & Eu-O3 & 2.575 \\
\hline Mn1-Mn1 & 2.995 & Eu-O3 & 2.085 \\
\hline Mn2-Mn2 & 2.976 & $<$ Eu-O $>=$ & 2.535 \\
\hline \multicolumn{4}{|c|}{ Selected bonding angles } \\
\hline O3-Mn1-O3 & $79.0(9)$ & 01-Mn2-O4 & $97.8(5)$ \\
\hline O3-Mn1-O4 & $173.8(8)$ & O1-Mn2-O2 & 93.2(1) \\
\hline O3-Mn1-O4 & $98.5(6)$ & O1-Mn2-O2 & $161.9(2)$ \\
\hline O3-Mn1-O2 & $94.5(1)$ & O4-Mn2-O2 & $99.0(6)$ \\
\hline O3-Mn1-O2 & $87.8(6)$ & $\mathrm{O} 2-\mathrm{Mn} 2-\mathrm{O} 2$ & $90.8(4)$ \\
\hline O4-Mn1-04 & 83.9(2) & Mn2-O1-Mn2 & $102.0(9)$ \\
\hline O4-Mn1-O2 & 87.1(7) & Mn1-O3-Mn1 & $101.9(0)$ \\
\hline O4-Mn1-O2 & 91.1(8) & Mn1-O4-Mn1 & $95.6(1)$ \\
\hline O2-Mn1-O2 & $177.6(1)$ & Mn1-O4-Mn2 & $131.2(5)$ \\
\hline O1-Mn2-01 & $78.0(9)$ & Mn1-O2-Mn2 & $127.0(9)$ \\
\hline
\end{tabular}

